\title{
A systematic review and meta-analysis of two different managements for supracondylar humeral fractures in children
}

\author{
Lin-Guo ${ }^{1,2}$, Xue-Ning Zhang ${ }^{1 *}$, Jian-Ping Yang ${ }^{3}$, Zhi Wang ${ }^{2 *}$, Yang $\mathrm{Qi}^{2}$, Shan-Zhu ${ }^{2}$ and Xiang-Hong Meng ${ }^{2}$
}

\begin{abstract}
Background: The objective of this meta-analysis was to illustrate the clinical outcomes and safety of two different managements for supracondylar humeral fractures in children.

Methods: In January 2018, a systematic computer-based search was conducted in PubMed, EMBASE, Web of Science, Cochrane Database of Systematic Reviews, and Google database. Data on patients prepared for two different managements for supracondylar humeral fractures in children were retrieved. The primary endpoint was the cosmetic and clinical outcomes based on the criteria of Flynn, ulnar nerve injury, and the occurrence of infection. After testing for publication bias and heterogeneity between studies, data were aggregated for random-effects models when necessary.
\end{abstract}

Results: Six clinical studies with 581 patients were ultimately included in the meta-analysis. There was no significant difference between the closed reduction and percutaneous cross-pinning, and open reduction and internal fixation in terms of the cosmetic and clinical outcomes based on the criteria of Flynn, ulnar nerve injury, and the occurrence of infection $(P>0.05)$.

Conclusions: Closed reduction and percutaneous pinning, and open reduction and internal fixation of supracondylar humeral fractures in children result in similar construct stability and functional outcome. More high quality randomized controlled trials are needed to identify this conclusion.

Keywords: Closed reduction, Supracondylar humeral fractures, Meta-analysis

\section{Background}

Supracondylar fracture of the humerus is the second most frequent types of bone injury in children [1, 2]. The occurrence of supracondylar fracture of the humerus account for 55 to $75 \%$ of patients with elbow fractures [3, 4]. For treatment of this fracture, closed reduction and percutaneous pinning, and open reduction and internal fixation were two common managements for supracondylar fracture of the humerus [5]. Ducic et al. [6] revealed that closed reduction and percutaneous pinning was associated with an increase of the

\footnotetext{
* Correspondence: zhangxuening09@qq.com; yingxiaozhang2011@qq.com; wangzhidoctor@qq.com; wangbaoguo2017@qq.com

'Department of Radiology, The Second Hospital of Tianjin Medical University, No 23 PingJiang Road Hexi District, Tianjin, China

${ }^{2}$ Department of Radiology, Tianjin Hospital, No 406 JieFang South Road Hexi District, Tianjin, China

Full list of author information is available at the end of the article
}

clinical outcomes. Kazimoglu et al. [7] found that closed reduction has equally clinical outcomes than open reduction. Until now, there is no universal agreement among orthopedic surgeons on the most appropriate treatment for supracondylar fracture of the humerus. Currently, there was no relevant meta-analysis that compared closed reduction and open reduction.

Thus, it is necessary to evaluate the efficacy and safety of two different managements for supracondylar humeral fractures in children. This meta-analysis aimed to illustrate the clinical outcomes and safety of two different managements for supracondylar humeral fractures in children. We hypothesize that closed reduction and percutaneous pinning, and open reduction and internal fixation has similar clinical result for supracondylar humeral fractures in children. 


\section{Methods}

This systematic review was reported according to the preferred reporting items for systematic reviews and meta-analyses (PRISMA) guidelines [8].

\section{Search strategies}

The following databases were searched in September 2016 without restrictions on location or publication types: PubMed (1950-January 2018), EMBASE (1974January 2018), the Cochrane Library (January 2018 Issue 3 ), and the Google database (1950-January 2018). The Mesh terms and their combinations used in the search were as follows: "supracondylar humeral fractures" OR "SCHF" AND "closed reduction" AND "open reduction". The reference lists of related reviews and original articles were searched for any relevant studies, including RCTs involving adult humans. Only articles originally written in English or translated into English were considered. When multiple reports describing the same sample were published, the most recent or complete report was used. This meta-analysis collected data from published articles and thus no ethic approval was necessary for this article.

\section{Inclusion criteria and study selection}

Patients: patients was diagnose as supracondylar fracture of the humerus surgery; intervention: closed reduction and percutaneous pinning as an intervention group; comparison: open reduction and internal fixation as a comparison group; outcomes: cosmetic and clinical outcomes based on the criteria of Flynn, ulnar nerve injury, and the occurrence of infection; study design: randomized controlled trials (RCTs) and non-RCTs. Two independent reviewers screened the title and abstracts of the identified studies after removing the duplicates from the search results. Any disagreements about the inclusion or exclusion of a study were solved by discussion or consultation with an expert. The reliability of the study selection was determined by Cohen's kappa test, and the acceptable threshold value was set at $0.61[6,7]$.

\section{Data abstraction and quality assessment}

A specific extraction was conducted to collect data in a pre-generated standard Microsoft ${ }^{\circ}$ Excel (Microsoft Corporation, Redmond, Washington, USA) file. The items extracted from relevant studies were as follows:

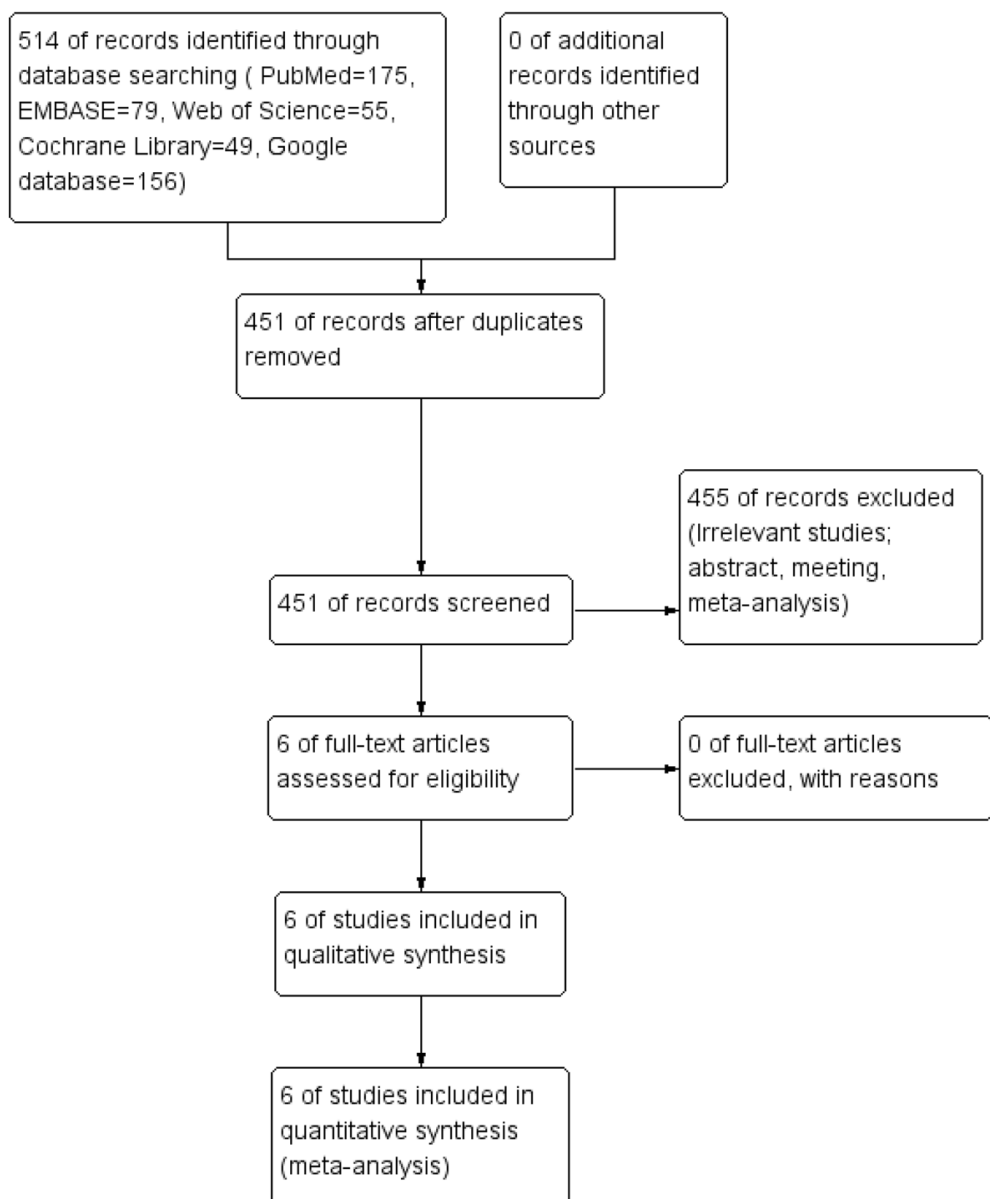

Fig. 1 Flowchart of study search and inclusion criteria 
Table 1 The general characteristic of the included studies

\begin{tabular}{|c|c|c|c|c|c|c|c|c|}
\hline Author & Country & $\begin{array}{l}\text { Type of } \\
\text { fracture }\end{array}$ & Age (year) & Intervention & Controls & Outcomes & Follow-up & Study \\
\hline Ducic 2016 [6] & Serbia & $\begin{array}{l}\text { Gartland Ila } \\
\text { Gartland IIb } \\
\text { Gartland III }\end{array}$ & 6.7 vs 6.1 & $\begin{array}{l}\text { Closed reduction with } \\
\text { percutaneous pinning }\end{array}$ & $\begin{array}{l}\text { Open reduction with } \\
\text { Kirschner wire fixation } \\
\text { (lateral approach) }\end{array}$ & $1,2,3,4$ & $11.2 \pm 2.3$ months & RCSs \\
\hline Kaewpornsawan 2001 [11] & Thailand & NS & 7.9 vs 6.8 & $\begin{array}{l}\text { Closed reduction with } \\
\text { percutaneous pinning }\end{array}$ & $\begin{array}{l}\text { Open reduction with } \\
\text { Kirschner wire fixation } \\
\text { (lateral approach) }\end{array}$ & $1,2,3,4$ & 12 months & RCTs \\
\hline Kazimoglu 2009 [7] & Turkey & Gartland III & 5.9 vs 6.5 & $\begin{array}{l}\text { Closed reduction and } \\
\text { percutaneous cross- } \\
\text { pinning }\end{array}$ & $\begin{array}{l}\text { Open reduction and } \\
\text { internal fixation } \\
\text { (lateral incision) }\end{array}$ & $1,2,3$ & 29.5 months & RCSs \\
\hline Keskin 2014 [12] & Turkey & NS & & $\begin{array}{l}\text { closed reduction and } \\
\text { percutaneous pinning }\end{array}$ & $\begin{array}{l}\text { open reduction and } \\
\text { percutaneous pinning } \\
\text { (middle incision) }\end{array}$ & $1,3,4$ & 3 months & RCSs \\
\hline Lu 2011 [13] & China & Gartland III & NS & $\begin{array}{l}\text { closed reduction and } \\
\text { pinning }\end{array}$ & $\begin{array}{l}\text { Open reduction } \\
\text { and pinning } \\
\text { (middle incision) }\end{array}$ & $1,2,3,4$ & 10 months & RCTs \\
\hline Ozkoc 2004 [14] & Turkey & Gartland III & 10.7 vs 7.6 & $\begin{array}{l}\text { closed reduction and } \\
\text { pinning }\end{array}$ & $\begin{array}{l}\text { Open reduction } \\
\text { and pinning } \\
\text { (posteromedial incision) }\end{array}$ & $1,2,3,4$ & 21 months & RCSs \\
\hline
\end{tabular}

1 cosmetic outcomes based on the criteria of Flynn, 2 clinical outcomes based on the criteria of Flynn, 3 ulnar nerve injury, 4 the occurrence of infection, PCTs prospective controlled trials

Table 2 The general characteristic of the included studies

\begin{tabular}{|c|c|}
\hline Author & Intervention \\
\hline Ducic 2016 [6] & Two crossed K-wires \\
\hline Kaewpornsawan 2001 [11] & $\begin{array}{l}\text { Three pins were inserted } \\
\text { laterally by two pins in } \\
\text { the upward direction, } \\
\text { percutaneously after } \\
\text { carefully protecting } \\
\text { the ulnar nerve. }\end{array}$ \\
\hline
\end{tabular}

Kazimoglu 2009 [7]

Keskin 2014 [12]

Lu 2011 [13]

Ozkoc 2004 [13]
Eleven patients had been treated with two lateral, 11 patients with one lateral and one medial, and 15 patients with two lateral and one medial K-wires.

Two Kirschner wires $(1.5 \mathrm{~mm}$ or $2.0 \mathrm{~mm}$ ) were placed traversing each other, one from medial and one from lateral aspect for percutaneous fixing while the elbow was locked in full flexion

Two Kirschner wires (1.5 mm) were placed traversing each other, one from medial and one from lateral aspect for percutaneous fixing while the elbow was locked in full flexion.
Controls

ns

Two pins were inserted into upward from the lateral side and one pin downward from the lateral side but the pin did not protrude into the medial condyle

Two pins were inserted into upward from the lateral side and one pin downward from the lateral side but the pin did not protrude into the medial condyle

If the patients having sufficient fracture healing, Kirschner wires were removed without giving anesthesia on an average of 3 weeks after the operation, and active and passive motion of the elbow were allowed

ns

The triangle towel suspends the elbow at $90^{\circ}$

Active elbow range of motion rehabilitation program was encouraged in the fourth week under the supervision of a physical therapist damages, cubitus varus, surgical site and pin tract infection, and other complications
Complications

Vascular and neurovascular complications

Ipsilateral forearm fracture, vascular injury, compartment syndrome, and abnormal growth and development

Infection, nerve injury and compartment syndrome
After 4 weeks in a plaster removed. Bothe groups concerning a program of

With maximum flexion of $90^{\circ}$ ns

Compartment syndrome, infection, nerve injuries
After the operation three to 4 weeks of dorsal long arm splint at $90^{\circ}$ 


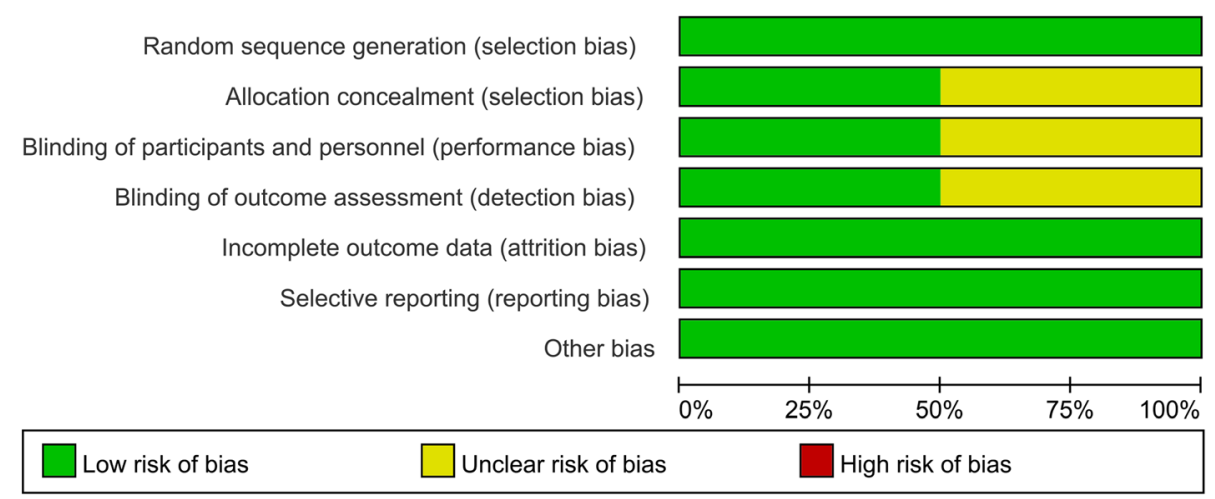

Fig. 2 The risk of bias graph

first author and publication year, country, sample size of the intervention and control groups, mean age of the intervention and control groups, the protocol of intervention and comparison groups, and follow-ups. Outcomes such as cosmetic and clinical outcomes based on the criteria of Flynn [9], ulnar nerve injury, and the occurrence of infection were abstracted and recorded in the spreadsheet. The criteria of Flynn were presented in Additional file 1. Data in other forms (i.e., median, interquartile range, and mean $\pm 95 \%$ confidence interval (CI)) were converted to the mean \pm standard deviation (SD) according to the Cochrane Handbook [10]. If the data were not reported numerically, we extracted these data using the "GetData Graph Digitizer" software from the published figures. All the data were extracted by two independent reviewers, and disagreements were resolved by discussion.

The quality of all included trials was independently assessed by two reviewers on the basis of the Cochrane Handbook for Systematic Reviews of Interventions, version 5.1.0 (http://handbook.cochrane.org) [10]. A total of seven domains were used to assess the overall quality: random sequence generation, allocation concealment, blinding of participant and personnel, blinding of outcome assessment, incomplete outcome data, selective reporting, and other bias. Each domain was measured as low bias, unclear bias, or high bias.

\section{Outcome measures and statistical analysis}

Dichotomous outcomes (cosmetic and clinical outcomes based on the criteria of Flynn [9], ulnar nerve injury, and the occurrence of infection) were expressed as a risk ratio (RR) with 95\% CI. Statistical significance was set at $P<0.05$ to summarize the findings across the trials. Variables in the meta-analysis were calculated using Stata software, version 12.0 (Stata Corp., College Station, TX, USA). Statistical heterogeneity was evaluated using the chi-square test and the $\mathrm{I}^{2}$ statistic. When there was no statistical evidence of heterogeneity $\left(I^{2}<50 \%, P>0.1\right)$, a fixed-effects model was adopted; otherwise, a random-effects model was chosen. Publication bias was tested using funnel plots. Publication bias was visually assessed using funnel plots and was quantitatively assessed using Begg's test.

\section{Results}

\section{Search results and quality assessment}

Flow of trials through the meta-analysis can be seen in Fig. 1. In the initial search, a total of 514 studies were identified from the electronic databases (PubMed $=175$, EMBASE $=79$, Web of Science $=55$, Cochrane Library $=$ 49 , Google database $=156$ ). Then, all papers were input into Endnote X7 (Thomson Reuters Corp., USA)

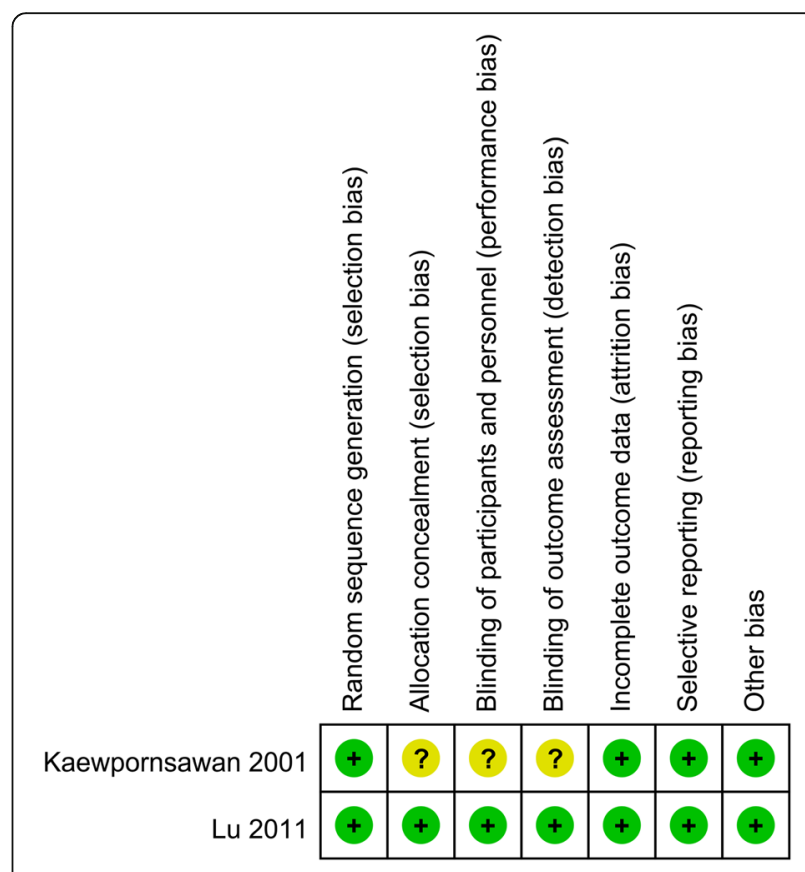

Fig. 3 Risk of bias of included randomized controlled trials. +, no bias; - , bias; ?, bias unknown 
Table 3 The Minors quality score of the non-RCTs

\begin{tabular}{|c|c|c|c|c|c|c|c|c|c|c|c|c|c|}
\hline \multirow[t]{2}{*}{ First author, year } & \multicolumn{13}{|c|}{ Minors scale } \\
\hline & 1 & 2 & 3 & 4 & 5 & 6 & 7 & 8 & 9 & 10 & 11 & 12 & Total \\
\hline Ducic 2016 [6] & 2 & 1 & 1 & 2 & 0 & 2 & 2 & 0 & 2 & 2 & 1 & 2 & 17 \\
\hline Kazimoglu 2009 [7] & 2 & 2 & 2 & 2 & 2 & 2 & 2 & 2 & 2 & 1 & 2 & 2 & 23 \\
\hline Keskin 2014 [12] & 2 & 2 & 0 & 2 & 0 & 2 & 2 & 0 & 2 & 1 & 1 & 2 & 16 \\
\hline Ozkoc 2004 [14] & 2 & 2 & 1 & 2 & 2 & 1 & 2 & 2 & 2 & 2 & 2 & 2 & 22 \\
\hline
\end{tabular}

Numbers 1-12 in heading signified the following: 1 a clearly stated aim, 2 inclusion of consecutive patients, 3 prospective collection of data, 4 endpoints appropriate to the aim of the study, 5 unbiased assessment of the study endpoint, 6 follow-up period appropriate to the aim of the study, 7 loss to follow-up less than $5 \%, 8$ prospective calculation of the study size, 9 an adequate control group, 10 contemporary groups; 11 baseline equivalence of groups, and

12 adequate statistical analyses

software for the removal of duplicate papers. A total of 451 papers were reviewed, and 455 papers were removed according to the inclusion criteria at abstract and title levels. Finally, a total of six studies were finally included in this meta-analysis $[6,7,11-14]$. The general characteristic of the included studies can be seen in Tables 1 and 2. All of the patients were children, and the mean age ranged from 5.9 to 10.7 years. The type of the fracture mainly focused on the Gartland II and III. The duration of follow-up ranged from 3 to 29.5 months.

\section{Quality of the included studies}

The quality of RCTs can be seen in Figs. 2 and 3, respectively. Randomized sequence generation was appropriate in one study and the other study was identified as unclear risk of bias. Other selection bias and other bias were unclear risk of bias. The quality of non-RCTs can be seen in Table 3 . The scores of the non-RCTs ranged from 16 to 23 .

\section{Results of the meta-analysis \\ Functional outcomes based on the criteria of Flynn}

Functional outcomes based on the criteria of Flynn were reported in three studies, and the pooled results indicated that there was no significant difference between the cosmetic outcomes based on the criteria of Flynn $(R R=1.08$, $95 \%$ CI $0.94,1.24, P=0.280$, Fig. 4). Functional outcomes based on the criteria of Flynn has no heterogeneity $\left(I^{2}=0\right.$. $0 \%, P=0.786$ ), which required a fixed-effects model that was performed to analyze the data. Funnel plot and Begg's test were used to identify the potential publication bias of the functional outcomes based on the criteria of Flynn, and results shown that the effect size was symmetrical and there was no publication bias (Figs. 5 and 6). In order to increase the robust of current outcome, sensitivity analysis was performed, and after removal each of the studies, the final outcomes was not changed (Fig. 7).

\section{Cosmetic outcomes based on the criteria of Flynn}

Cosmetic outcomes based on the criteria of Flynn were reported in three studies, and the pooled results indicated that there was no significant difference between the cosmetic outcomes based on the criteria of Flynn $(R R=0.97$, 95\% CI 0.83, 1.13, $P=0.700$, Fig. 8). Cosmetic outcomes based on the criteria of Flynn has no heterogeneity $\left(I^{2}=0\right.$. $0 \%, P=0.736$ ), which required a fixed-effects model that was performed to analyze the data.

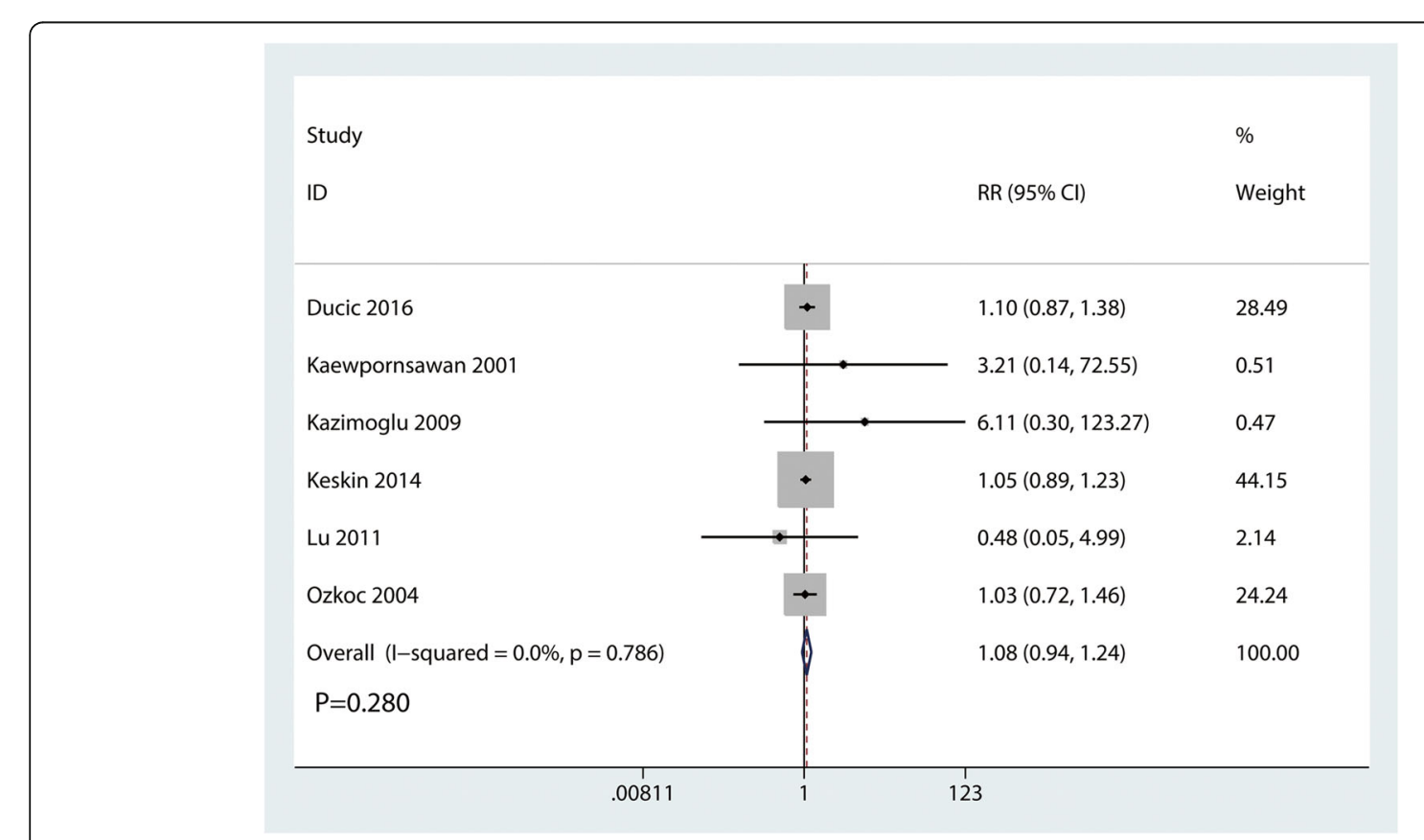

Fig. 4 Forest plots of the included studies comparing the cosmetic outcomes based on the criteria of Flynn 


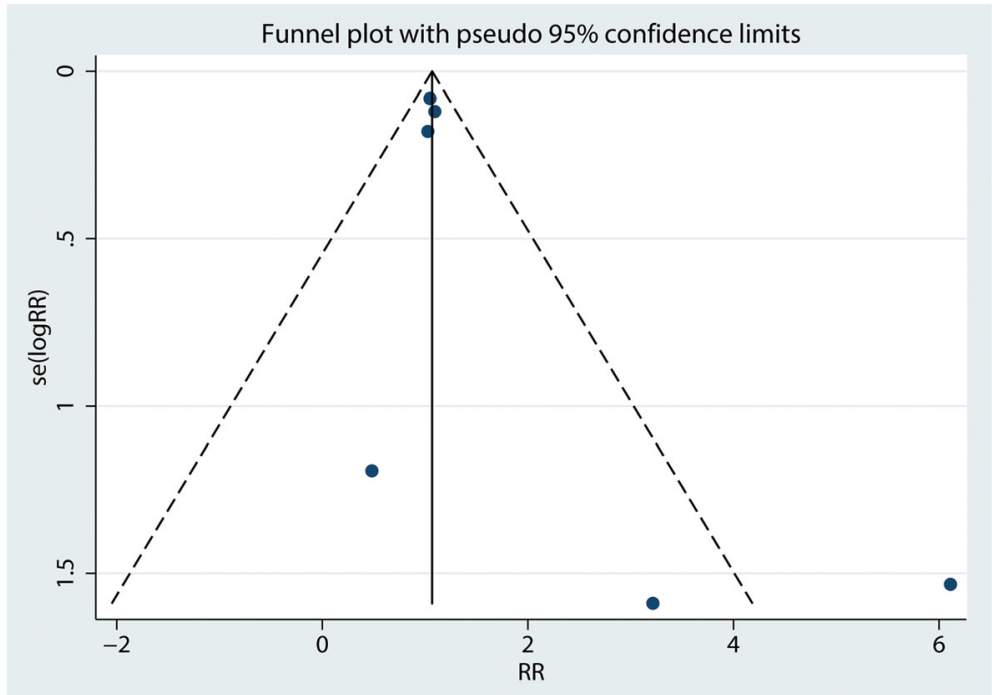

Fig. 5 Funnel plot of cosmetic outcomes based on the cosmetic outcomes based on the criteria of Flynn between the two groups

\section{Ulnar nerve injury}

Ulnar nerve injury were reported in three studies, and the pooled results indicated that there was no significant difference between the cosmetic outcomes based on the criteria of Flynn ( $\mathrm{RR}=0.86,95 \% \mathrm{CI} 0.36,2.02, P=0.725$, Fig. 9). Ulnar nerve injury has no heterogeneity $\left(I^{2}=0\right.$. $0 \%, P=0.786)$, which required a fixed-effects model that was performed to analyze the data.

\section{Occurrence of infection}

Occurrence of infection were reported in three studies, and the pooled results indicated that there was no significant difference between the occurrence of infection $(\mathrm{RR}=1.09,95 \% \mathrm{CI} 0.48,2.47, P=0.838$, Fig. 10). Occurrence of infection has no heterogeneity $\left(I^{2}=0.0 \%\right.$,
$P=0.741$ ), which required a fixed-effects model that was performed to analyze the data.

\section{Discussion}

This is the first systematic review and meta-analysis that comparing different managements for supracondylar humeral fractures in children. Results comprising four outcomes (cosmetic and functional outcomes based on the criteria of Flynn, ulnar nerve injury, and the occurrence of infection). Results shown that there was no significant difference between the above outcomes.

The ideal treatment for supracondylar humeral fractures is, according to many authors, closed reduction and percutaneous pinning. In current study, we found that closed reduction and percutaneous pinning has comparable

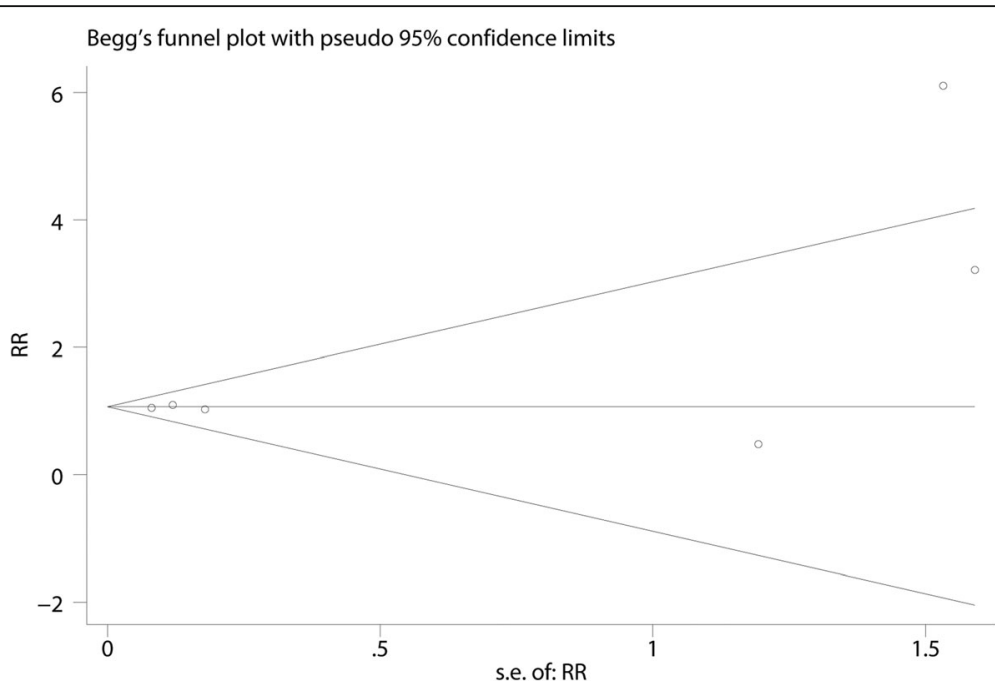

Fig. 6 Begg's test for the functional outcomes based on the criteria of Flynn 


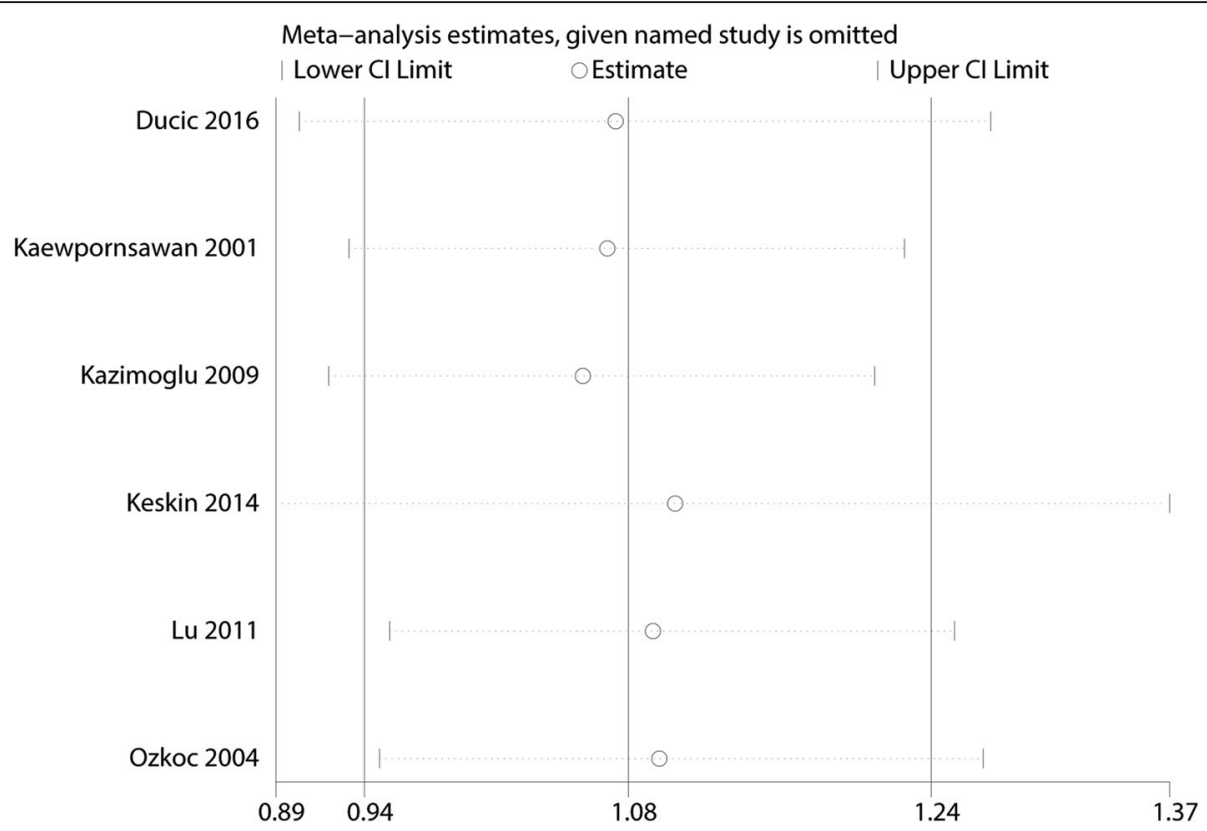

Fig. 7 Sensitivity analysis of the functional outcomes based on the criteria of Flynn

clinical outcomes according to the criteria of Flynn. Results shown that there was no significant difference between the cosmetic and functional outcomes $(P>0.05)$. Previously, a large number of studies initially tried closed reduction and pinning for supracondylar humeral fractures, and if closed reduction failed and other complications occurred, open reduction was tried. Therefore, open reduction groups generally included the more complicated patients and the clinical outcomes were always bad than closed reduction group. Mulpuri et al. [15] conducted a systematic review and included 44 studies, and they suggested that closed reduction with pin fixation ( 2 or 3 laterally introduced pins) for patients with displaced supracondylar fractures of the humerus.

And, there was no significant difference between the occurrence of ulnar nerve injury $(\mathrm{RR}=0.86,95 \% \mathrm{CI} 0.36$,

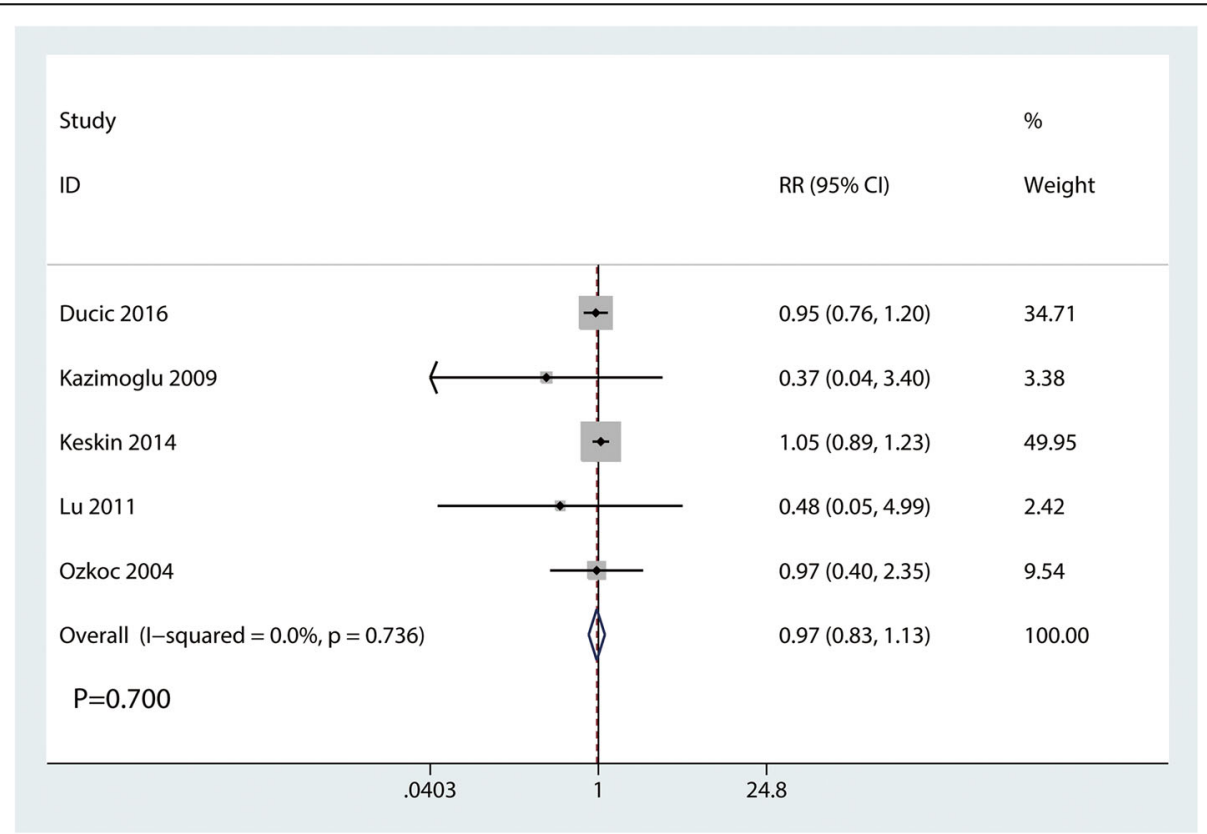

Fig. 8 Forest plots of the included studies comparing the cosmetic outcomes based on the criteria of Flynn 


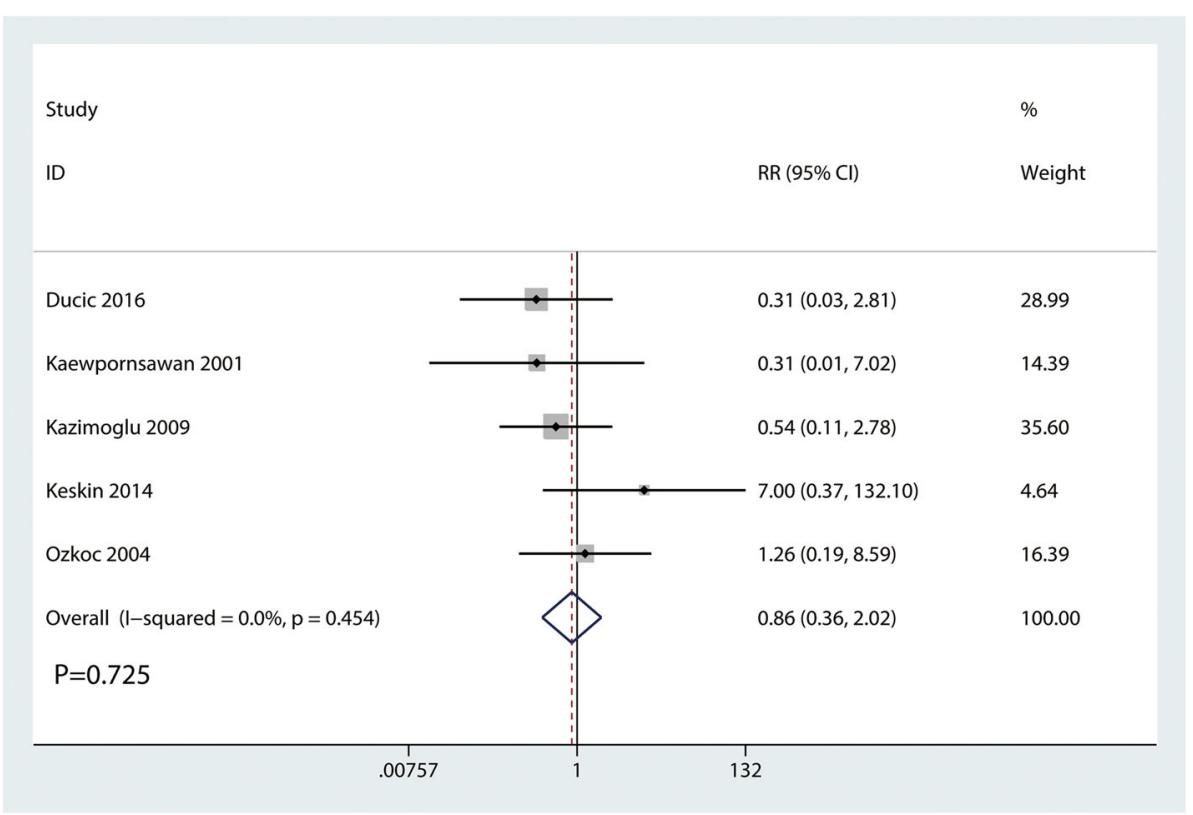

Fig. 9 Forest plots of the included studies comparing the occurrence of ulnar nerve injury

2.02, $P=0.725)$. Two lateral pins was an effective and relative stable method to avoid of iatrogenic ulnar nerve injury. Though, cross-pinning was associated with an increase of the occurrence of ulnar nerve injury, long-terms follow-up revealed that ulnar nerve injury will recover spontaneously without complication $[16,17]$. Thus, closed reduction was more preferable than open reduction for consideration of the ulnar nerve injury.
The occurrence of infection has been reported as 2.4-6. $6 \%$ [18-20]. In current meta-analysis, the occurrence of infection for the closed reduction and percutaneous pinning and open reduction was 6.41 and $7.14 \%$, respectively. There was no significant difference between the two groups. These rates were also comparable with reports of previous literatures. Kazimoglu et al. [7] revealed that there was no significant difference between the open group and closed

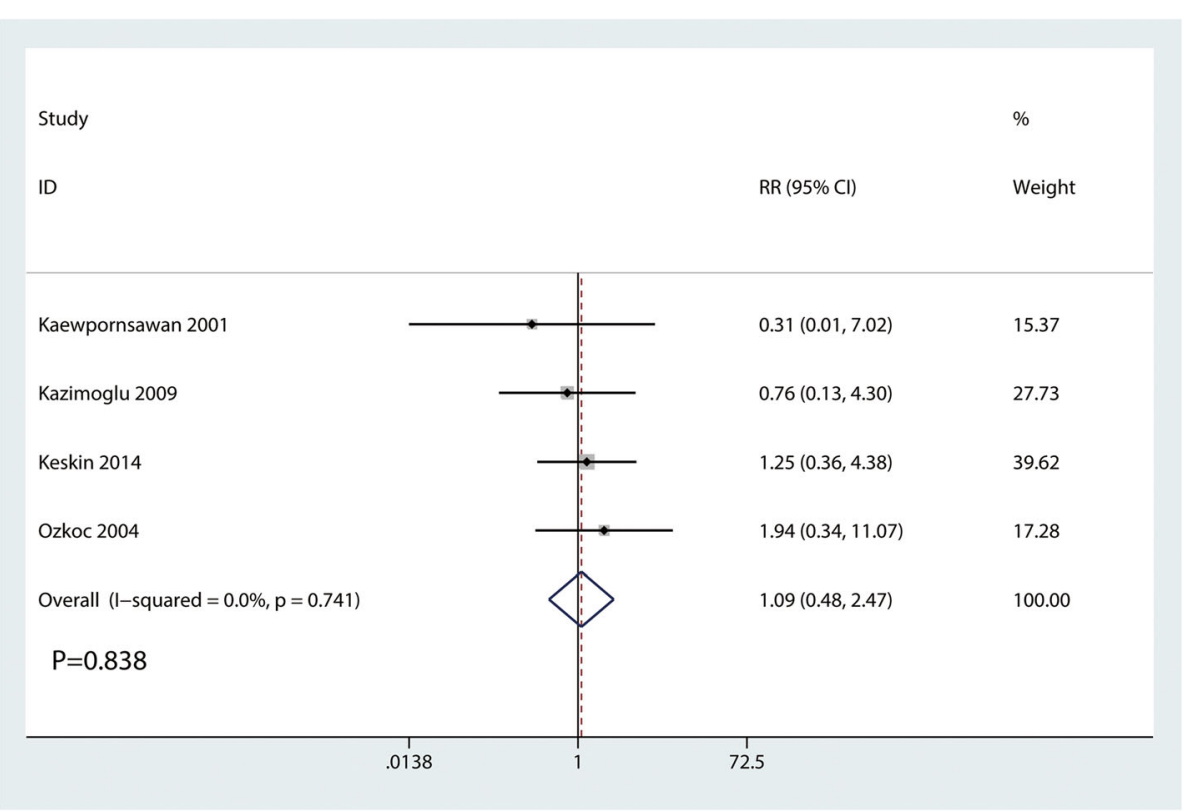

Fig. 10 Forest plots of the included studies comparing the occurrence of infection 
group in terms of the pin tract infection. And all infectious patients were responded well to the oral antibiotic treatment.

There were several limitations in this meta-analysis: (1) only 6 potential studies were finally included, the effect size was relative small; (2) follow-up was relatively short and thus, the potential of these management complications may be underestimated; (3) the management of the K-wires was different and thus, may cause the heterogeneity for the outcomes; (4) subgroup analysis was not performed since the number of the included studies was limited and thus, more RCTs were need to further identify the clinical outcomes of these two managements.

\section{Conclusion}

In conclusion, closed reduction and percutaneous pinning, and open reduction and internal fixation of supracondylar humeral fractures in children result in similar construct stability and functional outcome. And there was no significant difference between the two managements as for the complications. Because the sample size and the number of included studies were limited, a multi-center RCT is needed to identify the effects of closed reduction and percutaneous pinning for supracondylar humeral fractures in children.

\section{Additional file}

Additional file 1: Table S1. Flynn Criteria for Grading Supracondylar Humerus Fractures. (DOCX $15.4 \mathrm{~kb}$ )

\section{Abbreviations}

Cl: Confidence interval; PRISMA: Preferred reporting items for systematic reviews and meta-analyses; RCTs: Randomized controlled trials; RR: Relative risk; SD: Standard deviation; WMD: Weighted mean differences

\section{Availability of data and materials}

We state that the data will not be shared because all the raw data are present in the figures included in the article.

\section{Authors' contributions}

LG and XNZ conceived the study design. JPY and ZW performed the study, collected the data, and contributed to the study design. YQ and SZ prepared the manuscript. XHM and LG edited the manuscript. All authors read and approved the final manuscript.

\section{Ethics approval and consent to participate}

None

\section{Competing interests}

The authors declare that they have no competing interests.

\section{Publisher's Note}

Springer Nature remains neutral with regard to jurisdictional claims in published maps and institutional affiliations.

\section{Author details}

'Department of Radiology, The Second Hospital of Tianjin Medical University, No 23 PingJiang Road Hexi District, Tianjin, China. ²Department of Radiology, Tianjin Hospital, No 406 JieFang South Road Hexi District, Tianjin, China.

${ }^{3}$ Department of Pediatrics, Tianjin Hospital, Tianjin, China.
Received: 12 February 2018 Accepted: 5 April 2018

Published online: 07 June 2018

References

1. Begovic N, Paunovic Z, Djuraskovic Z, Lazovic L, Mijovic T, Babic S. Lateral pinning versus others procedures in the treatment of supracondylar humerus fractures in children. Acta Orthop Belg. 2016;82:866-71.

2. Carrazzone OL, Belloti JC, Matsunaga FT, et al. Surgical interventions for the treatment of supracondylar humerus fractures in children: protocol of a systematic review. JMIR Res Protoc. 2017;6:e232.

3. Sahin E, Zehir S, Sipahioglu S. Comparison of medial and posterior surgical approaches in pediatric supracondylar humerus fractures. Niger J Clin Pract. 2017;20:1106-11.

4. Naik LG, Sharma GM, Badgire KS, Qureshi F, Waghchoure C, Jain V. Cross pinning versus lateral pinning in the management of type III supracondylar humerus fractures in children. J Clin Diagn Res. 2017;11:Rc01-rc03.

5. Patriota G, Assuncao Filho CA, Assuncao CA. What is the best fixation technique for the treatment of supracondylar humerus fractures in children? Rev Bras Ortop. 2017:52:428-34.

6. Ducic S, Bumbasirevic M, Radlovic V, et al. Displaced supracondylar humeral fractures in children: comparison of three treatment approaches. Srp Arh Celok Lek. 2016:144:46-51.

7. Kazimoglu C, Cetin M, Sener M, Agus H, Kalanderer O. Operative management of type III extension supracondylar fractures in children. Int Orthop. 2009;33:1089-94.

8. Liberati A, Altman DG, Tetzlaff J, et al. The PRISMA statement for reporting systematic reviews and meta-analyses of studies that evaluate healthcare interventions: explanation and elaboration. BMJ. 2009;b2700:339.

9. Flynn JC, Matthews JG, Benoit RL. Blind pinning of displaced supracondylar fractures of the humerus in children. Sixteen years' experience with longterm follow-up. J Bone Joint Surg Am. 1974;56:263-72.

10. GS HJ. Cochrane handbook for systematic reviews of interventions version 5.1.0. 2011. http://handbook.cochrane.org.

11. Kaewpornsawan K. Comparison between closed reduction with percutaneous pinning and open reduction with pinning in children with closed totally displaced supracondylar humeral fractures: a randomized controlled trial. J Pediatr Orthop B. 2001;10:131-7.

12. Keskin $\mathrm{D}$, Sen $\mathrm{H}$. The comparative evaluation of treatment outcomes in pediatric displaced supracondylar humerus fractures managed with either open or closed reduction and percutaneous pinning. Acta Chir Orthop Traumatol Cechoslov. 2014;81:380-6.

13. Lu X, Luo B, Li K Different methods for treatment of patients with supracondylar fractures of the humerus: a randomized study. China Modern Medicine. 2011;18:74-5.

14. Ozkoc G, Gonc U, Kayaalp A, Teker K, Peker TT. Displaced supracondylar humeral fractures in children: open reduction vs. closed reduction and pinning. Arch Orthop Trauma Surg. 2004;124:547-51.

15. Mulpuri K, Wilkins K. The treatment of displaced supracondylar humerus fractures: evidence-based guideline. J Pediatr Orthop. 2012;32(Suppl 2):S143-52.

16. Kalenderer $\mathrm{O}$, Reisoglu $\mathrm{A}$, Surer $\mathrm{L}$, Agus $\mathrm{H}$. How should one treat iatrogenic ulnar injury after closed reduction and percutaneous pinning of paediatric supracondylar humeral fractures? Injury. 2008;39:463-6.

17. Lyons JP, Ashley E, Hoffer MM. Ulnar nerve palsies after percutaneous cross-pinning of supracondylar fractures in children's elbows. J Pediatr Orthop. 1998;18:43-5.

18. Boyd DW, Aronson DD. Supracondylar fractures of the humerus: a prospective study of percutaneous pinning. J Pediatr Orthop. 1992;12:789-94.

19. Cheng JC, Shen WY. Limb fracture pattern in different pediatric age groups: a study of 3,350 children. J Orthop Trauma. 1993;7:15-22.

20. Mehlman CT, Crawford AH, McMillion TL, Roy DR. Operative treatment of supracondylar fractures of the humerus in children: the Cincinnati experience. Acta Orthop Belg. 1996;62(Suppl 1):41-50. 